\title{
A DESCONSTRUÇÃO DA NARRATIVA SOBRE MULHER E FUTEBOL NA MÍDIA: O DRIBLE DO BLOG DIBRADORAS
}

\author{
THE DECONSTRUCTION OF THE NARRATIVE ABOUT \\ WOMAN AND SOCCER IN THE MEDIA: THE DRIBBLE OF THE \\ DIBRADORAS BLOG
}

\section{LA DESCONSTRUCCIÓN DE LA NARRATIVA SOBRE MUJER Y FÚTBOL EN LOS MEDIOS DE COMUNICACIÓN: LA FINTA DEL BLOG DIBRADORAS}

\section{RESUMO}

Este artigo visa analisar como ocorre a desconstrução da narrativa cultural hegemônica acerca da relação entre mulher e futebol na mídia, com o foco, especificamente, no blog Dibradoras, hospedado no site UOL. Por meio da Análise do Discurso - de orientação francesa -, estuda-se um corpus de dez matérias. A partir delas, identifica-se que os sentidos municiam cinco diferentes Formações Discursivas: denuncista, demarcatória, distintiva, da mudança e da resistência. Todas elas c $\neg$ onvergem para a descontinuidade de relações de gênero e poder predominantes, desfazendo visões sociais historicamente sedimentadas.

\section{Palavras-chave:}

Mulher; Futebol; Cultura; Mídia; Discurso.

\section{ABSTRACT}

This article aims to analyze how the deconstruction of the hegemonic cultural narrative about the relationship between woman and football occurs in the media, focusing specifically on the Dibradoras blog, from which we analyzed ten subjects considering the French Discourse Analysis method. Then we identified that the senses provide five different Discursive Formations: denouncing, demarcation, distinctive, change and resistance. All of them converge towards the discontinuity of prevailing gender and power relations, undoing historically settled social views.

\section{Keywords:}

Woman; Football; Culture; Media; Discourse.

\section{RESUMEN}

Este artículo pretende analizar cómo ocurre la deconstrucción de la narrativa cultural hegemónica sobre la relación entre mujer y fútbol en los medios de comunicación, con el enfoque en el blog Dibradoras, alojado en el sitio UOL. Por medio del Análisis del Discurso de orientación francesa -, se estudia un corpus de diez materiales. A partir de ellas, se identifica que los sentidos agregan cinco diferentes Formaciones Discursivas: de denuncia, de demarcación, distintiva, de cambio y de la resistencia. Todas ellas convergen para la discontinuidad de las relaciones de género y de poder predominantes, deshaciendo visiones sociales históricamente sedimentadas.

\section{Palabras clave:}

Mujer; Fútbol; Cultura; Medios de comunicación; Discurso. 


\section{INTRODUÇÃO}

Este artigo é fruto de uma discussão feita em um trabalho de conclusão de curso que trata da desconstrução da narrativa cultural hegemônica a respeito da relação entre mulher e futebol na mídia, de modo particular no blog Dibradoras Para tanto, estruturamos nossa discussão, primeiro, olhando para a teoria dos Estudos Culturais. Ainda que de modo conciso, trabalhamos um conceito de cultura que abrange a forma como compreendemos o mundo, as instituições e as relações sociais, os comportamentos cotidianos, as práticas comunicacionais, o contexto histórico e os jogos de poder existentes na sociedade, incluindo as disputas entre ideias hegemônicas e contrahegemônicas dos diferentes grupos sociais. Feminismo e gênero são estudados no bojo desse viés.

Na terceira seção, tratamos do contexto histórico da construção da narrativa cultural da mulher no ambiente do futebol, seja como jogadoras, árbitras, jornalistas, técnicas e torcedoras, apresentando as ideias hegemônicas e machistas propagadas na sociedade. $\mathrm{Na}$ quarta, abordamos a metodologia empregada e a seleção dos materiais examinados. Na quinta seção, temos a análise, em que refletimos sobre os sentidos produzidos por esse discurso jornalístico. Por último, expressamos as considerações a respeito dos resultados do trabalho

\section{FEMINISMO, GÊNERO E ESTUDOS CULTURAIS: BREVE NOÇÃO CONCEITUAL}

Os Estudos Culturais tratam de possíveis significados para determinadas práticas sociais dentro de uma cultura, objetivando compreender as suas influências na vida da sociedade. Os Estudos Culturais pesquisam "as relações entre a cultura contemporânea e a sociedade, isto é, suas formas culturais, instituições e práticas culturais, assim como, suas relações com a sociedade e mudanças sociais [...]" (ESCOSTEGUY, 1998, p. 88).

Hall (2003) considera que o feminismo foi uma das rupturas teóricas no trabalho do Centro de Estudos Culturais Contemporâneos. Este movimento reorganizou o campo de diversas maneiras, tais como: a proposição da questão do pessoal como político e sua influência na mudança do objeto de estudo desse campo; a expansão da noção de poder que era trabalhada só no âmbito da esfera pública; "a centralidade das questões de gênero e sexualidade para a compreensão do próprio poder"; a abertura para tratar do subjetivo e do sujeito; a reabertura da fronteira entre "a teoria social e a teoria do Inconsciente - a psicanálise" (HALL, 2003, p. 208-209). Com os Estudos Culturais, as novas visões acerca de cultura e feminismo, as mulheres conseguiram mais visibilidade na sociedade, até mesmo para discutir as experiências que vivenciavam.

O feminismo objetiva alcançar a igualdade de gênero na sociedade, evidenciando as desigualdades existentes entre mulheres e homens em uma estrutura machista da cultura. Mas, conforme Mouffe (1993), o feminismo não deve ser entendido como uma luta pela realização da igualdade para um grupo com essência e identidade comuns, mas sim, uma luta contra as múltiplas formas pelas quais a categoria mulher é construída como subordinada.

Ao longo do tempo, se fortaleceu a crença de que a mulher era naturalmente inferior ao homem, o que, portanto, justificaria as desigualdades sociais de gênero. Contudo, essas disparidades são estabelecidas na dimensão cultural. Beauvoir (1970) buscou mostrar, em sua obra, que não há explicação - por exemplo, na Biologia, na Psicanálise e no Materialismo Histórico - para a ideia de que os homens são superiores e devem dominar as mulheres, as quais devem ser submissas e sofrer com a opressão. Para refutar qualquer determinismo, ela explica que "ninguém nasce mulher, tornase mulher" (BEAUVOIR, 1967, p. 9).

As feministas utilizam a noção de gênero para se referir "à organização social da relação entre os sexos" (SCOTT, 1995, p. 72). Assim, ela se apresenta como um elemento das relações sociais e de poder. O uso desse termo rejeita o determinismo biológico e suas explicações de que a subordinação feminina se deve porque "as mulheres têm a capacidade para dar à luz e de que os homens têm uma força muscular superior" (SCOTT, 1995, p. 75)

Gênero é "uma categoria social imposta sobre um corpo sexuado" (SCOTT, 1995, p. 75). Desse modo, as noções e os papéis definidos para cada gênero são construídos 
socialmente e variam de acordo com a sociedade e com a época. Antes mesmo de nascer, o ser humano já tem características e objetos atribuídos a ele que concordem com o gênero que consideram que deveria se identificar. Essas distinções entre os gêneros se transformam em relações desiguais, que são reproduzidas em todos os espaços sociais e em todas as instituições, sobretudo, na mídia e no jornalismo.

\section{MULHERES, HOMENS E FUTEBOL: PARTICIPAÇÃO E DOMINAÇÃO}

A Constituição Federal Brasileira de 1988 assegura a igualdade entre homens e mulheres (BRASIL, 1988). Contudo, isso não se reproduz na prática. Quando é dito que todos os homens nascem livres, a "máxima" vale para o público masculino, porque "as mulheres não nascem livres, elas não têm liberdade natural" (PATEMAN, 1993, p. 21). Para Beauvoir, "O mundo sempre pertenceu aos machos" (1970, p. 81).

No caso do futebol, ele é visto como expressão de valores considerados masculinos, um instrumento fortalecedor da masculinidade e uma recusa aos valores ditos femininos e à feminilidade. Ao longo da história, as mulheres foram afastadas e excluídas desse esporte simplesmente por serem mulheres, pois essa prática não correspondia com os ideais culturais de gênero feminino e de feminilidade, que aprendemos por meio da socialização como adequados para elas. O futebol é, portanto, um ambiente marcado pela presença de homens, mas as mulheres buscam conquistar seu espaço nesse universo como jogadoras, árbitras, jornalistas, técnicas e torcedoras.

No Brasil, o futebol é um elemento social, faz parte da cultura e, para muitos, é a paixão nacional. Todavia, vemos facilmente as diferenças entre o futebol masculino e feminino. No masculino, há mais investimento, transações milionárias entre os clubes, jogadores com altos salários e comissões técnicas e de arbitragens que são formadas, na sua maioria, por homens.

As mulheres brasileiras praticam futebol desde o início do século XX. Em 1921, há o registro da que pode ser considerada a primeira partida de futebol feminino do Brasil. 0 jogo aconteceu entre mulheres dos bairros de Tremembé e Cantareira, em São Paulo. Vale ressaltar que as primeiras práticas de futebol feminino eram vistas como performances ou shows e não como um jogo ou partida.

Passados alguns anos, foram usadas muitas explicações, até mesmo científicas e médicas, para limitar a prática esportiva das mulheres, reforçando a condição de sexo frágil e reassegurando a noção de resguardar a mulher para o que era considerado seu papel primordial, isto é, a maternidade. Inclusive, em um decreto do governo em 1941, as mulheres foram proibidas de praticar esportes incompativeis com a sua natureza, como o futebol. Essa proibição só foi revogada em 1979.

Em 2019, a Federação Internacional de Futebol (Fifa) informou em um estudo que o
Brasil tem 15 mil mulheres jogando futebol de maneira organizada, disputando campeonatos amadores ou profissionais (MENDONÇA, 2019a). Além disso, nas primeiras seis edições da Copa do Mundo de Futebol Feminino, as principais emissoras brasileiras das redes fechada e aberta não faziam a exibição da competição. Apenas em 2019, na oitava edição da copa, houve cobertura pela televisão aberta, com a Rede Globo transmitindo todos os jogos da seleção brasileira e a Band algumas partidas.

Já na arquibancada, foi permitido às mulheres assistirem aos jogos, porém, muitas vezes, com o intuito de embelezar os estádios. E era em lugares reservados na arquibancada, "como se fossem guetos na torcida" (FRANZINI, 2005, p. 25). Hoje, existem torcidas organizadas femininas em alguns clubes do Brasil, as quais realizam também ações de combate ao machismo.

Na arbitragem, historicamente, as mulheres também lutam para conquistar seu espaço. A criação da categoria Fifa para árbitras mulheres ocorreu apenas em 1995 - para os homens existe desde a década de 1950 (MONTEIRO, 2016). A falta dessa categoria atrasou e dificultou o crescimento e o aperfeiçoamento da arbitragem feminina, assim como, geralmente elas continuam sendo escaladas para atuar em divisões e em partidas com menor visibilidade no cenário do futebol brasileiro.

No quadro de arbitragem da Fifa, existem 1076 homens e 426 mulheres, incluindo árbitros principais e assistentes, ou seja, 
menos de 30\% são mulheres, mas nem todas elas podem atuar nas competições masculinas, que apresentam um teste físico diferente e mais rigoroso, e, dentre as poucas que poderiam, nenhuma está no topo do ranking das suas federações nacionais (MENDONÇA, 2018). Já na Confederação Brasileira de Futebol (CBF), elas representam apenas $10,26 \%$ do quadro de arbitragem, pois são 752 homens, dos quais 248 são árbitros principais, 355 são assistentes e 149 são analistas de desempenho, e 86 mulheres, sendo 18 árbitras, 59 assistentes e nove analistas (NINA, 2019).

$\mathrm{Na}$ função de treinadora, a situação não é diferente. Esse campo de atuação é muito restrito para mulheres, já que "ainda é um espaço de domínio masculino, em especial, nas equipes de alto nível" (GOELLNER, 2005b, p. 95). Um dos motivos para essa dificuldade é o de que, na sociedade, ainda há o pensamento de que cargos de gestão, direção e comando devem ser ocupados por homens, porque são eles que teoricamente - apresentariam atributos como liderança, autoridade e força.

No jornalismo esportivo, elas também têm dificuldades para estar. Coelho (2004) explica que era impossivel imaginar mulheres nas editorias de esporte das redações até o início da década de 1970 e que as jornalistas esportivas, na maioria das vezes, são encaminhadas para cobrir modalidades como vôlei, basquete e tênis, e dificilmente, futebol e automobilismo, o que demonstra 0 machismo presente nessas áreas. Desse modo, vemos que as jornalistas são afastadas de certos esportes que consideram ser um espaço para homens trabalharem.

Na rede de televisão fechada, apenas $13 \%$ dos profissionais trabalhando em programas esportivos jornalísticos são mulheres, quase todas elas na reportagem (FREITAS; MONTAGNANA; CARNEIRO, 2016). Em programas de mesas redondas, dificilmente vemos mulheres no debate, e quando há, elas são tratadas mais como musas ou figuras decorativas do que como profissionais capazes de discutir sobre as pautas.

O machismo e o desrespeito estão presentes no cotidiano delas, pois recebem ofensas e são assediadas nos estádios, nas redes sociais e enfrentam situações de conotação sexual na realização do seu trabalho. Em 2018, foi organizado o Movimento Deixa Ela Trabalhar por um grupo de jornalistas com o objetivo de pedir respeito e igualdade para exercerem suas atividades jornalísticas. Com relatos de 52 mulheres que atuam na mídia esportiva, foi lançada a campanha a fim de denunciar e combater o assédio moral e sexual sofrido por elas nos estádios nas redações e nas ruas (BAGATINI, 2018). A campanha ganhou repercussão e outros profissionais de comunicação, jogadores, torcedores e clubes apoiaram a iniciativa.

Diante disso, o futebol ainda é um espaço em que a participação das mulheres permanece restrita e elas são julgadas ou afastadas dele por motivos relacionados a valores e características da condição de ser mulher. Também é considerado que o futebol masculiniza a mulher que o pratica ou a que está envolvida em qualquer uma das atuações, colocando em dúvida até a sua sexualidade. Para Goellner (2005a, p.148) essa ideia de masculinização representa admitir que este é um esporte masculino e que, quando jogado por elas, deve "evitar que sejam transpostos alguns limites culturalmente construídos e identificados como inerentes a cada gênero" e precisa feminizar estas mulheres, construindo uma narrativa de representação hegemônica de feminilidade.

No reforço de todos esses estereótipos e noções equivocadas, ainda há a mídia. Não faz muito tempo, o futebol feminino era tratado sempre com trocadilhos sexuais e clichês irônicos, tal qual: elas batem um bolão (MENDONÇA, 2019b), com as mulheres aparecendo em posições de objetificação e sexualização nas fotografias. Hoje, é comum ver a mídia tratando as atletas em um ideal de superação ou vitimismo, - que não contribui para que elas alcancem a igualdade no ambiente do futebol.

\section{CAMINHOS METODOLÓGICOS}

Empregamos a Análise de Discurso - de vocação francesa - para compreender a desconstrução da narrativa cultural hegemônica a respeito da mulher no futebol na mídia, mais precisamente no blog Dibradoras. Essa técnica engloba as relações entre quem diz, por que diz, o que é dito e como é dito em uma abordagem social e cultural. Todo discurso é produzido por um sujeito e direcionado a outro 
(s), estabelecendo uma comunicação. É através do discurso que podemos observar a relação entre língua e ideologia (ORLANDI, 2013). Assim, o discurso é uma atividade produtora de sentidos, a qual também depende das experiências sociais e culturais do sujeito que o construiu.

O discurso jornalístico é um discurso narrativo (MARQUES, 2008) e a narrativa é uma construção discursiva. Nesta pesquisa, são analisados os sentidos expressos nos discursos de produtos jornalísticos que, por sua vez, impactam nas narrativas acerca de determinados assuntos. 0 propósito é mostrar como o discurso do blog Dibradoras contribui para a desconstrução da narrativa cultural hegemônica.

Esse blog foi criado em 2015 e traz matérias que tratam de mulheres no mundo do esporte, especialmente em relação ao futebol, e sobre todas as áreas de atuação dentro desse meio, seja como atleta, árbitra, torcedora, técnica, gestora ou diretora nos cenários nacional e internacional. O nome do blog é em referência ao uso comum no universo futebolístico da palavra dibre ao invés de drible. O Dibradoras é produzido por duas jornalistas, Renata Mendonça e Roberta Nina, e uma publicitária, Angélica Souza. Esse blog é vinculado à empresa brasileira UOL (Universo Online), pertencente ao Grupo Folha.

Neste artigo, são analisados dez textos do blog que foram publicados de janeiro a julho de 2019. Escolhemos matérias que tratavam de futebol e, a partir disso, as que abordavam as cinco temáticas centrais analisadas neste estudo: arbitragem, futebol feminino, jornalismo, técnica esportiva e torcida. A criação e a organização destas categorias são produto da exploração feita no blog (são estes os temas majoritários) e a ideia é contemplar cada uma das cinco temáticas, dando uma visão panorâmica sobre os sentidos que as cercam. Para tanto, selecionamos os textos que apresentavam marcas discursivas de maior relevância para compreender o processo de desconstrução. Assim, são analisados os elementos textuais (títulos, intertítulos e textos) de duas matérias de cada categoria.

\section{ANÁLISE DE DADOS}

$\mathrm{Na}$ análise dos discursos existentes nos dez textos do blog Dibradoras, observamos que os sentidos produzidos podem ser agrupados em cinco Formações Discursivas (FDs), as quais são definidas "como aquilo que numa formação ideológica dada - ou seja, a partir de uma posição dada em uma conjuntura sócio-histórica dada determina o que pode e deve ser dito" (ORLANDI, 2013, p. 43). Tais FDs são apresentadas nas seções a seguir. Os trechos dos textos que as sustentam estão separados em sequências discursivas (SDs) e as marcas que consideramos que exemplificam as nossas constatações estão grifadas em itálico.

BOTANDO A BOCA NO TROMBONE: A REALIDADE DAS MULHERES NO FUTEBOL

Com base nos textos jornalísticos analisados. notamos que o blog Dibradoras apresenta a realidade enfrentada pelas mulheres nos mais diversos setores do ambiente futebolístico. Para Garcia (2011, p. 104), as feministas lutam e trabalham pela emancipação, buscando a liberdade e desmascarando todas as "falácias viris", pois cada grupo, a partir de sua realidade, se dedicou a discutir temas relacionados às mulheres e às relações de poder que impregnam tudo. Por isso, a necessidade de revelar as condições impostas a elas na sociedade, inclusive no futebol. No blog, as jornalistas assumem uma postura denuncista (FD) para evidenciar e ressaltar as situações que as mulheres passam. A seguir, mencionamos alguns exemplos que reforçam essa FD:

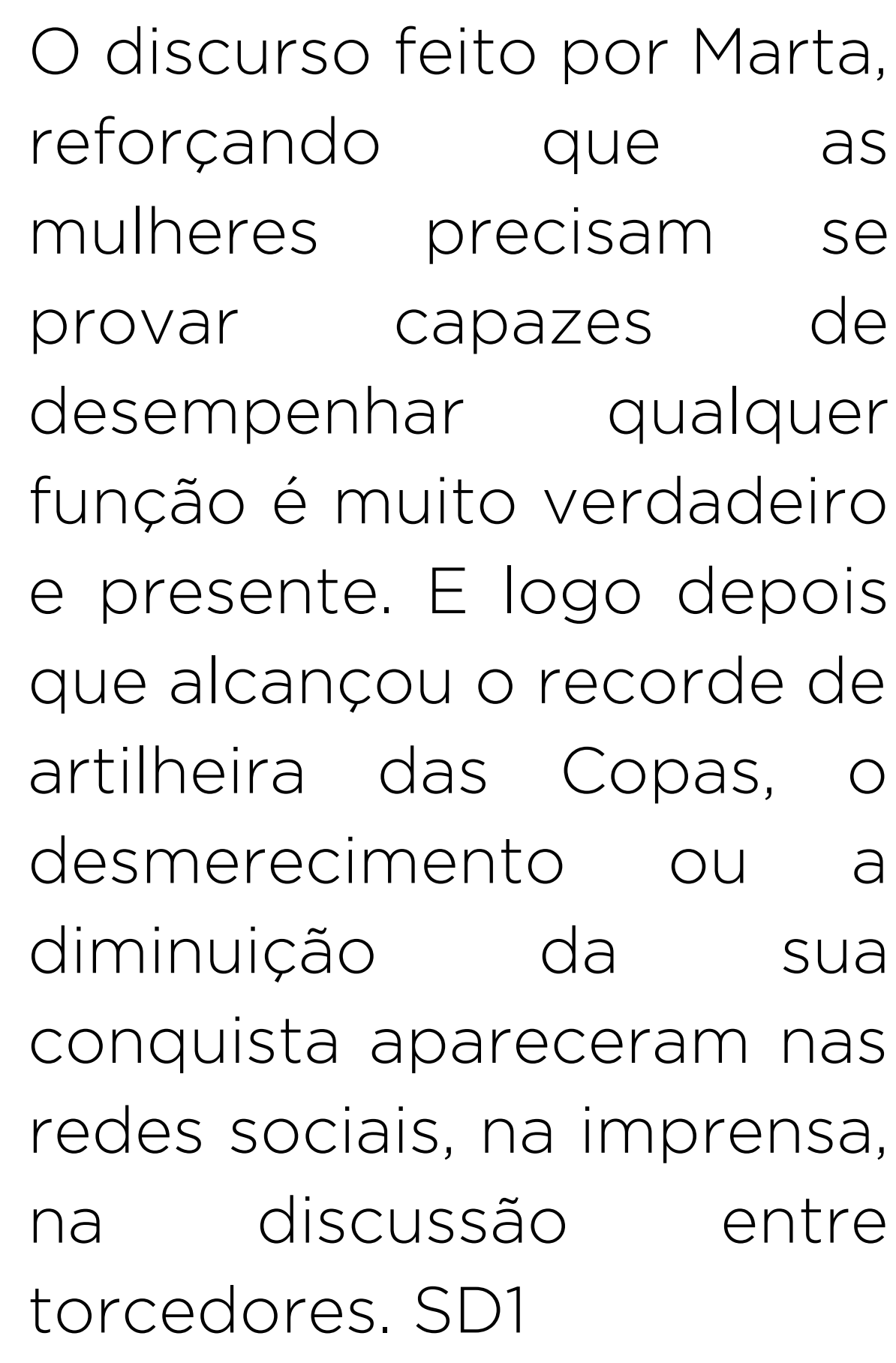

Na SD1, é evidenciado algo que acontece frequentemente com as mulheres na sociedade e no futebol, que é a ideia de que elas precisam provar a todo instante sua competência para desempenhar determinada atividade. $\mathrm{Na}$ frase subsequente, a autora aponta mais um dos feitos da jogadora Marta e apresenta que ocorreram reações negativas em três âmbitos distintos. O primeiro, as redes sociais, as quais são atualmente um dos principais meios em que os assuntos 
repercutem de forma imediata. O segundo, a imprensa, salientando que a mídia também tem seu papel nas desconfianças e nos questionamentos que surgem em relação às conquistas das mulheres. $\bigcirc$ terceiro, a discussão entre os torcedores que reproduzem o comportamento de desmerecerem os feitos das mulheres. Estes três espaços mencionados reiteram pensamentos e desenvolvem ações que são perpetuados na cultura machista da nossa sociedade.

De modo geral, a mídia constrói, através dos seus discursos, narrativas sobre as mulheres que são reproduzidas pelas pessoas e se tornam concepções hegemônicas. Cruz (2008) considera que as práticas discursivas dominantes da mídia reforçam valores dominantes e tradicionais a respeito delas, constituindo uma forma de violência simbólica de gênero dentro da sociedade. Assim, quem está no ambiente futebolístico consome esses discursos e tem seu comportamento orientado pelo pensamento hegemônico e dominante de que este é um espaço do qual as mulheres não deveriam participar.

Nunca se teve tanta atenção da mídia e talvez por isso, nunca se teve tanta atenção da CBF para falar sobre esse tema. A contratação de Pia veio como uma resposta a quem cobrava uma pessoa mais capacitada e qualificada para comandar a seleção principal e pode também servir como um escudo para a confederação que nunca olhou como deveria para a modalidade, e agora tenta usar a treinadora como a solução para todos os problemas. SD2

A SD2 abarca um discurso bastante crítico. No começo, já é reforçada a ideia da falta de atenção da mídia. Observamos que a mídia tradicional, responsável pelo discurso jornalístico dominante, pouco trata ou nem trata da realidade do futebol feminino brasileiro. A jornalista ainda aborda a falta de atenção da entidade que gerencia o futebol feminino para destacar o descaso existente com a modalidade no Brasil. Depois, a autora faz uma análise da situação, apontando que a contratação da técnica pode ter outros interesses que não apenas os de realmente trabalhar para melhorar o futebol feminino. Há, ainda, o peso da palavra nunca, repetida várias vezes durante o texto, para chamar a atenção que determinados fatos estão ocorrendo, alterando o cenário. A jornalista está colocando em evidência as situações que envolvem o futebol feminino, porque, no Brasil, ele continua rodeado de estereótipos e invisibilidades.

A partir do que foi discutido nessa FD - a qual entendemos como denuncista -, compreendemos que o blog expõe e critica a realidade enfrentada pelas mulheres nesse ambiente. Silva (2010, p. 50) pondera que talvez, no século XXI, existam "dúvidas sobre a necessidade de se refletir sobre as relações de gênero, poder e desigualdade", visto que as transformações culturais cada vez mais aludem às conquistas das mulheres e à igualdade de gênero - devido às reivindicações do movimento feminista. No entanto, vemos cotidianamente que $o$ gênero feminino e as mulheres ainda são tratados como inferiores ao masculino e aos homens, refletindo-se em uma relação desigual nos setores da sociedade. especialmente no futebol.

No blog Dibradoras, notamos que as jornalistas "botam a boca no trombone" para revelar e descrever a realidade das mulheres no futebol evidenciando os problemas e o que há de errado neste meio. Este discurso, além de permitir que isso seja visto, procura mudanças para essa realidade, acarretando na desconstrução da narrativa cultural hegemônica da relação das mulheres com o futebol em todos os sentidos.

\section{DISCRIMINAÇÃO DE GÊNERO: LUGAR DE MULHER É ONDE ELA QUISER}

Nos textos analisados, percebemos alguns relatos de casos de assédio e de agressão contra mulheres no ambiente futebolístico, com as entrevistadas contando essas situações. Conforme Garcia (2011, p. 18), o "machismo é um discurso da desigualdade", baseado na crença da superioridade dos homens. Ele é reproduzido nas atitudes das pessoas, indicando que a discriminação de gênero é uma prática social que está firmemente enraizada na sociedade. A seguir, temos trechos que exemplificam esta FD, que chamamos de demarcatória.

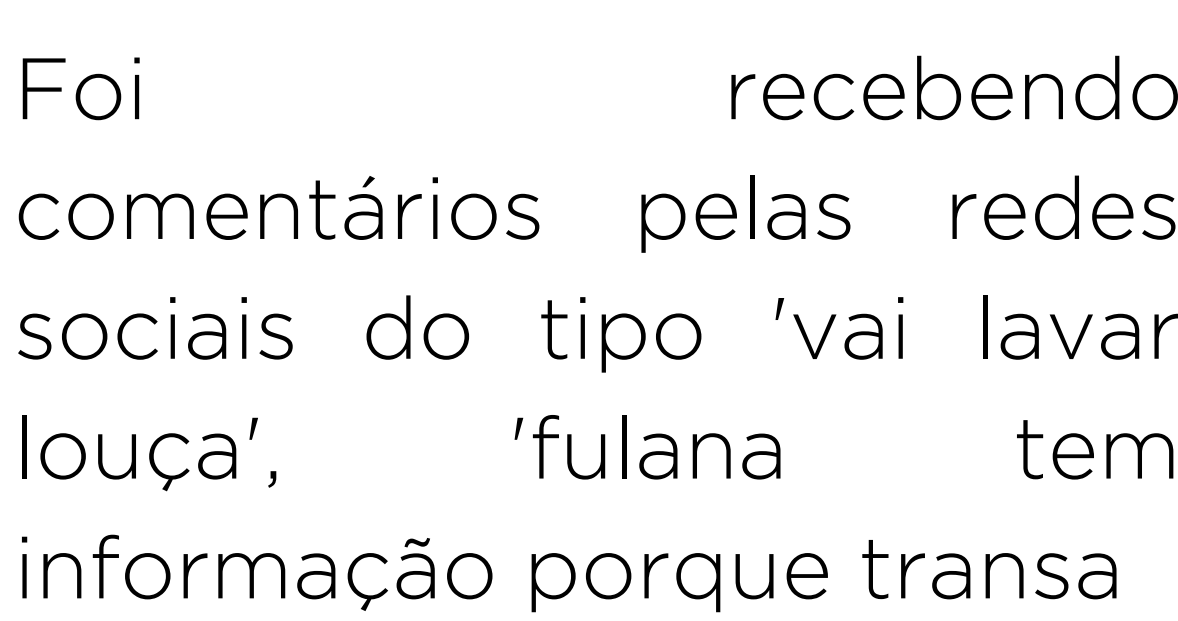
comentários pelas redes sociais do tipo 'vai lavar louça', 'fulana tem informação porque transa 
com jogador', que eu comecei a entender o nível do machismo. Eu passei a me desconstruir e também, a parar de julgar $O$ que outras mulheres fazem e como agem. O que eu vou esperar de 'haters' na rede social? Pra mim é muito pior ver cara que trabalha com você usando seu comentário com palavras diferentes e ganhando crédito só por ser homem. É ver homens fazendo cara feia enquanto você fala num debate só pelo fato de ser uma mulher falando. Ou quando todo mundo te atropela enquanto você tenta falar e não consegue. Isso pra mim é muito pior, porque são caras que estão em pé de igualdade com você e estão te tratando dessa forma", disse. SD3

No discurso da SD3, aparecem os estereótipos que as pessoas julgam estar associados às mulheres e também à descrença de que elas poderiam ser profissionais competentes para realizar seus trabalhos. Reparamos que a entrevistada explica que os comentários a fizeram entender a realidade que enfrenta e que não deveria criar juízo a respeito do que outras mulheres fazem, a qual é uma noção que o movimento feminista busca mostrar de que as experiências não podem ser generalizadas, porque são mulheres diferentes. Em seguida, vemos que a entrevistada conta sobre situações que passou para mostrar que os colegas não a respeitavam como profissional e não a tratavam com igualdade por ser uma mulher. Assim, fica claro que o apoio é difícil até de quem está envolvido no meio, porque os colegas de profissão também reproduzem o mesmo comportamento preconceituoso
É inaceitável que a gente precise escrever aqui de novo sobre o quão repudiável é esse tipo de atitude. "Olha, você não pode beijar a coleguinha que você não conhece sem $\mathrm{O}$ consentimento dela, ok?" - alguns homens parecem pedir para que os tratem da maneira mais infantil possível, não é mesmo? SD4

Na primeira frase da SD4, a jornalista mostra sua indignação, ressaltando que esse discurso é recorrente no blog. Em seguida, ela faz um questionamento em tom irônico para comunicar o recado aos homens, além de um comentário indicando a forma como alguns deles pedem para ser tratados e pergunta para o público se concorda com isso. Nesse trecho, podemos compreender que a autora utiliza uma linguagem com ironia e sarcasmo para fazer críticas aos casos de assédio e de violência e para repreender esse tipo de comportamento que faz com que a mulher seja discriminada apenas por ser mulher.

Com esta FD, entendemos que as jornalistas trazem os casos de assédio e agressão para serem conhecidos e discutidos e tentam tirar a "aura" de normalidade dos casos de machismo que acontecem, sobremaneira, com mulheres vinculadas ao futebol. Atualmente, a questão da violência contra elas vem cada vez mais sendo discutida na sociedade, porém, ainda, vemos que certos estereótipos e atitudes indevidas - como a culpabilização da vítima seguem sendo perpetuados, inclusive pelo jornalismo. Biroli
(2011, p. 74) pondera que a mídia difunde os estereótipos e colabora para a naturalização deles, "confirmando cotidianamente determinadas visões de mundo, em detrimento de outras". Isso contribui para o aumento e a sustentação dessa violência visto que o pensamento machista - de que mulheres são inferiores aos homens - não é rompido.

Identificamos, no Dibradoras, um trabalho para visibilizar os casos de violência contra mulheres no futebol e fazer a crítica destas situações, dando indicadores para as mudanças e exigindo-as - que podemos entender como uma contribuição do feminismo. Com uma postura indignada e revoltada, as autoras demonstram descontentamento e o tratamento dado nas matérias evidencia o quanto esse tema é delicado e indispensável à discussão pela igualdade de gênero. Nessa tarefa, o discurso das jornalistas baliza fronteiras - por isso o englobamos numa FD demarcatória, indicando que o lugar de mulher é onde ela quiser - uma frase muito representativa para as feministas - que rompe com a ideia de que existem lugares específicos para elas

\section{DOIS PESOS, DUAS MEDIDAS: COTEJAMENTO ENTRE MULHERES E HOMENS}

Ao longo da análise, notamos que aparecem trechos em que as autoras estabelecem comparações entre a realidade do futebol feminino e a do masculino, buscando mostrar as diferenças existentes e, da mesma forma, as diferenciações 
entre homens e mulheres por causa do gênero. O feminismo "ressalta as tensões e contradições que encerram todos esses discursos que intencionalmente confundem o masculino com o universal" (GARCIA, 2011, p. 14). Sendo assim, O blog Dibradoras apresenta um discurso que contesta e se opõe à diferenciação de gênero motivada pelo fato de considerarem os homens superiores às mulheres e, portanto, com diferenças de tratamento justificáveis. Em seguida, apresentamos fragmentos que tratam desta FD, intitulada de distintiva.

O Sport enfrenta inúmeras
dificuldades financeiras, é
verdade, está afundado em
dívidas, mas alguém
conseguer imaginar
qualquer categoria de uma
equipe masculina do time
pernambucano treinando
nessas condições?
Impossível. Só que é o time
feminino, então tudo bem,
acontece. SD5

Na SD5, há um exemplo das condições as quais o futebol feminino está sujeito no Brasil. As autoras questionam se os atletas homens poderiam passar por essa situação também e já dão a resposta que não é possível de acontecer. Isso porque sabemos que o futebol feminino é desvalorizado e apresenta condições precárias que não contribuem para o seu desenvolvimento. $\bigcirc$ trecho termina em tom irônico. O uso da expressão tudo bem, indicando que tudo estava de acordo e era algo aceitável para o futebol feminino, nesse contexto, assinala a crítica a essa realidade. Reconhecemos a ironia porque pressupomos as crenças e os valores da autora, os quais não concordariam com esta situação presente no discurso.

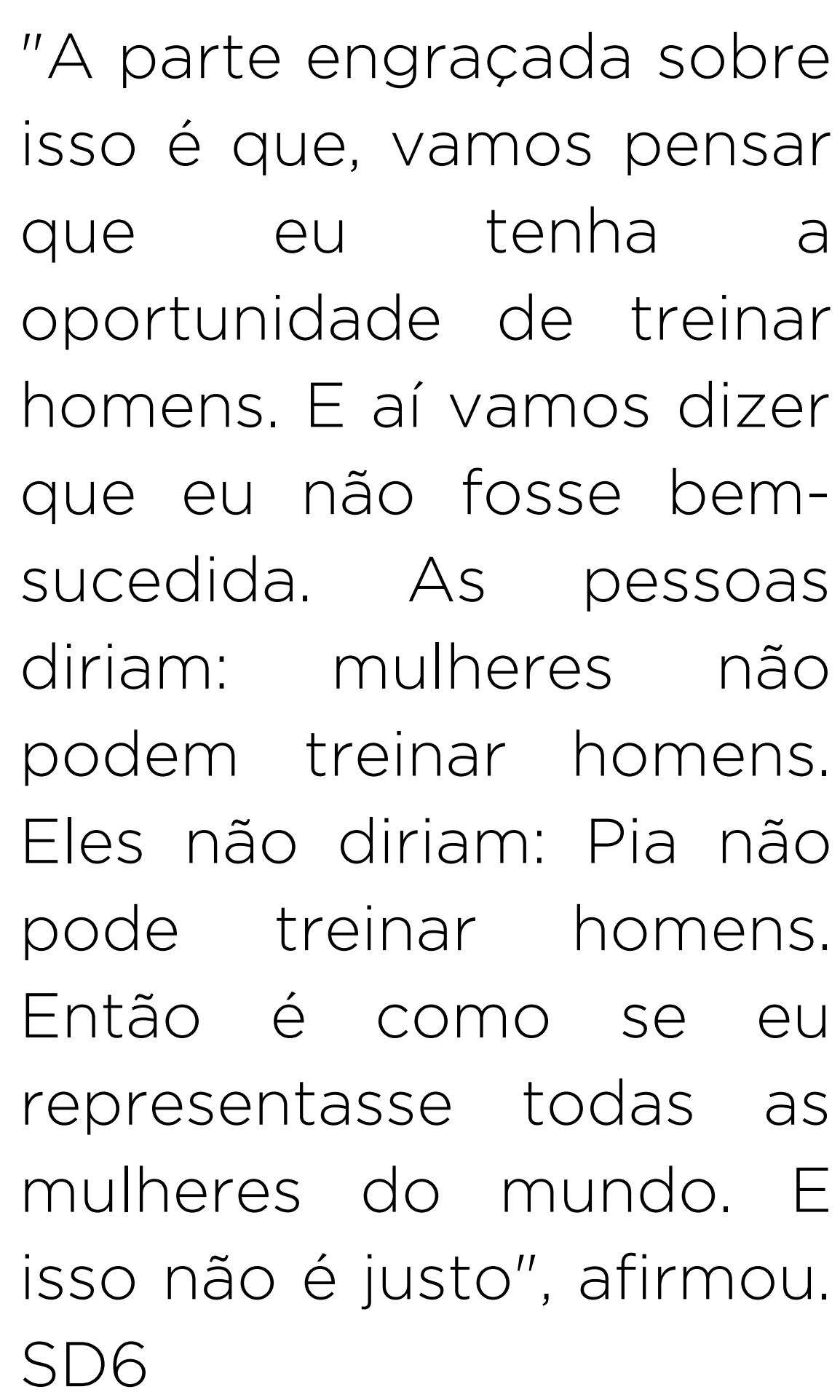

Na SD6, a fala da entrevistada apresenta mais uma diferença entre homens e mulheres nesse âmbito. $\bigcirc$ uso do termo engraçada indica algo cômico, que, nesse caso, é dito em tom irônico. Percebemos que as mulheres são tratadas de modo indevido porque o que uma faz representa a totalidade delas, enquanto com os homens isso não ocorre. Logo, fica claro que se uma mulher comete um erro, todas as mulheres são julgadas a partir disso. Notamos que é uma situação desigual e contrária à equidade entre os gêneros e, mais uma vez, o discurso jornalístico insiste em que existem dois pesos, duas medidas.

Na análise desta FD, constatamos que mulheres e homens são tratados de maneira completamente diferente em situações semelhantes e similares, por esse motivo temos a denominação dois pesos, duas medidas. Essa diferenciação é baseada no critério do gênero. Por isso, as "tensões entre a garantia formal de liberdade individual para as mulheres e a reprodução cotidiana de barreiras ao exercício dessa mesma liberdade são um

problema central para o feminismo contemporâneo" (BIROLI, 2012, p. 7).

Vemos que, embora estejam inseridas em uma sociedade democrática, há uma relação desigual. É como se existissem preferências e interesses que as mulheres podem ter e fazer e outras que não podem. Logo, quando elas têm esses comportamentos considerados impróprios, há esse tratamento diferente com condições distintas de um homem na mesma situação. $\bigcirc$ discurso jornalístico do blog Dibradoras evidencia, visibiliza e problematiza essas desigualdades.

\section{MUDANÇAS NO CENÁRIO FUTEBOLÍSTICO}

Esta parte da análise refere-se aos trechos em que são mostradas mudanças culturais que estão acontecendo e as exigências por mudanças de parte das autoras e das entrevistadas a fim de que as mulheres sejam respeitadas e alcancem a igualdade de gênero no ambiente futebolístico. O blog Dibradoras mostra que a prática discursiva pode contribuir para reproduzir a sociedade como ela é ou para transformá-la. Observemos, a seguir, alguns exemplos dessa FD, que sumarizamos como de mudança.

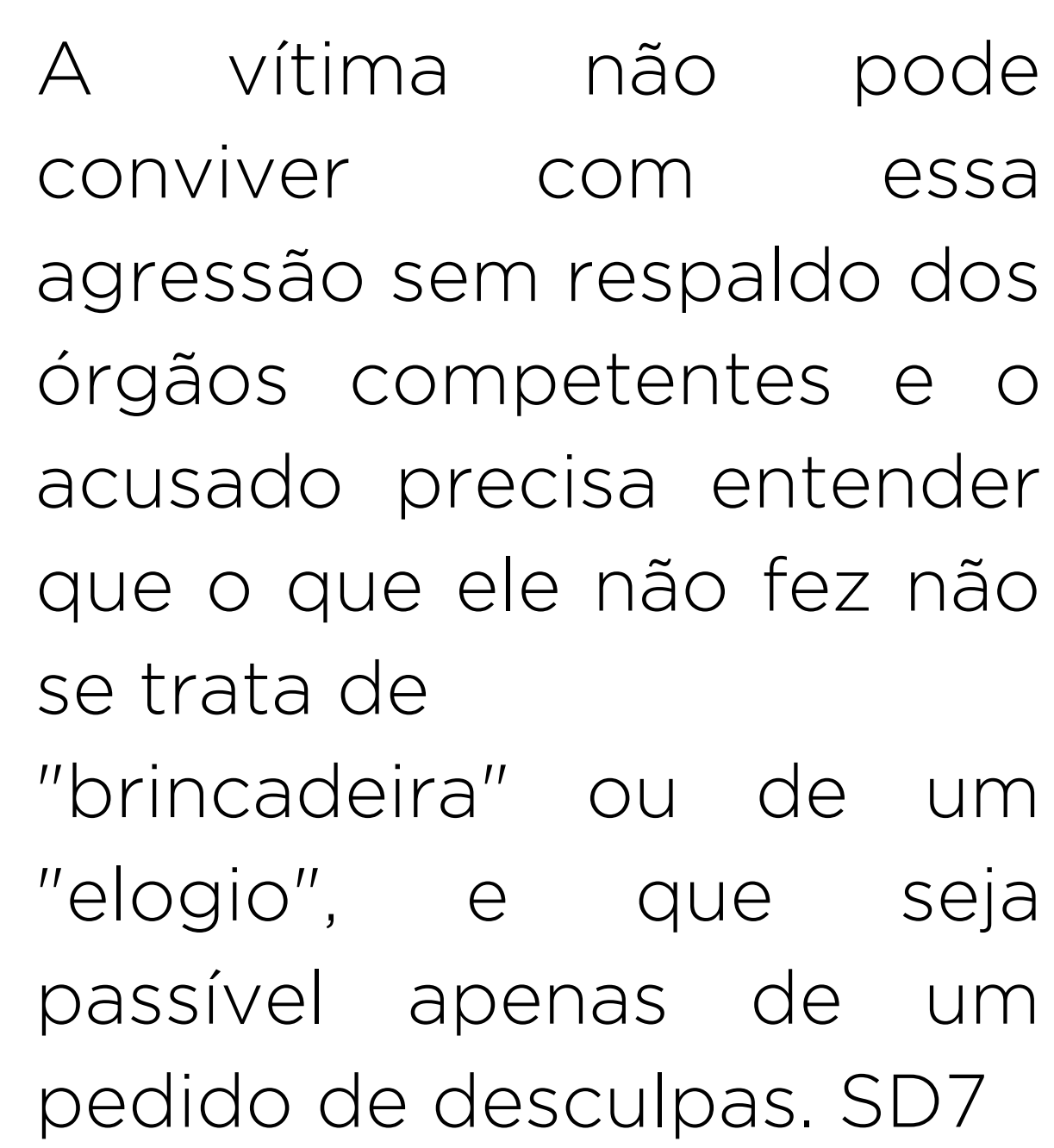


Na SD7, a jornalista, em uma postura indignada, menciona aspectos relevantes da situação atual, destacando a necessidade de fazer o agressor entender que aquela atitude é errada e não é insignificante para a mulher que sofreu. É possivel depreender uma exigência pela mudança dessa realidade. torno da Copa do Mundo Feminina é histórico e significativo. Se compararmos com quatro anos atrás, a relevância do modalidade cresceu vertiginosamente dentro e fora dos gramados. SD8

A SD8 demonstra a modificação no envolvimento com o futebol feminino nos últimos tempos. A autora frisa a importância histórica desse movimento dos torcedores, ressaltando o crescimento do interesse e do envolvimento deles com a modalidade até mesmo fora do campo.

Nesta FD, notamos as mudanças que estão acontecendo e as cobranças para que a realidade das mulheres seja modificada. Gustafson e Nascimento (2017, p. 33) explicam que "a redução das desigualdades de gênero [...] passa por mudanças nos discursos que constroem as realidades sociais". O jornalismo, na sua função social, deve propiciar transformações na cultura em favor da igualdade em todos os sentidos, inclusive de gênero. No blog, o discurso reverbera as mudanças e faz novas exigências para que essa igualdade seja obtida nesse meio, dando visibilidade para outros pontos de vista sobre o mundo

\section{EMPODERAMENTO E IGUALDADE DE GÊNERO}

O aspecto do empoderamento feminino e da luta pela igualdade de gênero é marcante nos textos do blog Dibradoras. A mulher, apesar de todas as conquistas no mundo do esporte, "tem muito que politicar para alcançar a igualdade que the é de direito" (CAPITANIO, 2005, p. 94). O discurso, reproduzido tanto nas falas das entrevistadas quanto no próprio texto escrito pelas jornalistas, incentiva um movimento de resistência contra a cultura machista da nossa sociedade. Analisemos os seguintes trechos que exemplificam esta FD, cognominada de resistência.

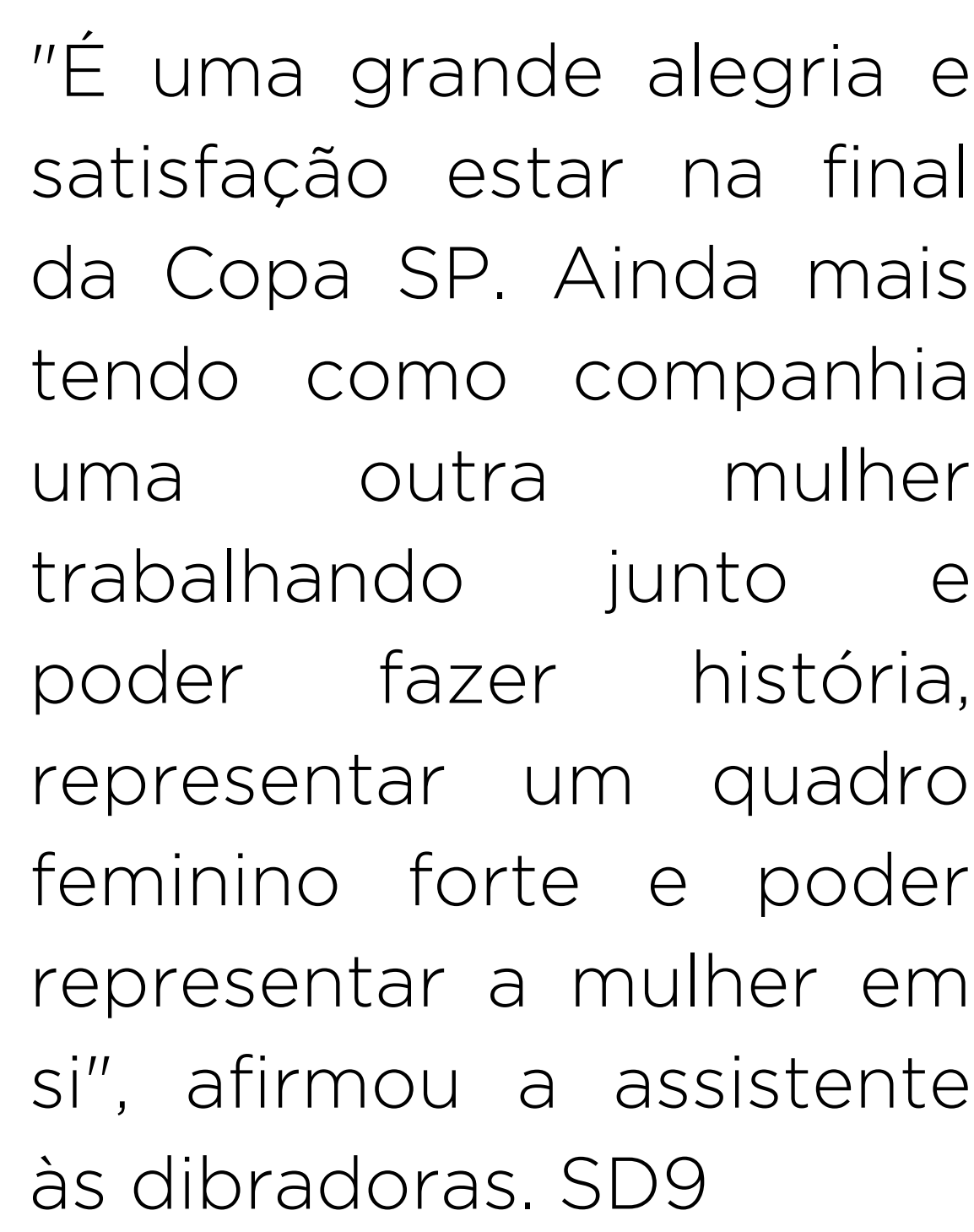
representar a mulher em si", afirmou a assistente às dibradoras. SD9

Na SD9, a entrevistada ressalta a importância do acontecimento - pela primeira vez, ter três mulheres no quinteto de arbitragem da final da Copa SP. Nesse caso percebemos que a própria assistente se sente no papel de fazer história e com o poder de representação para outras mulheres, o que denota o empoderamento feminino. 0 emprego da expressão quadro feminino forte não remete ao aspecto físico, mas sim da força dessas mulheres de lutar por seu espaço em um ambiente de predominância masculina.

De todas as formas,
Renata e Raquel
ressaltaram a importância
do respeito ao trabalho do
árbitro em geral,
independentemente

do gênero. "O árbitro merece o respeito porque é um ser humano como qualquer outro que está ali trabalhando", afirmou Raquel. SD10

A SD10 remete a um discurso de pedir respeito a todos os árbitros por serem seres humanos como quaisquer outros. Podemos notar que a entrevistada e a autora fazem questão de frisar que o gênero do profissional não pode e não deve interferir no seu trabalho e na forma como é tratado. Elas destacam o aspecto primordia e substancial - ser humano para justificar o pedido pela igualdade.

Nesta FD, o discurso das jornalistas apresenta dois elementos feministas: o empoderamento e a igualdade de gênero, que consubstanciam a resistência. Para Horochovski e Meirelles (2007, p. 486), empoderar é o processo pelo qual indivíduos e organizações "angariam recursos que lhes permitam ter voz, visibilidade, influência e capacidade de ação e decisão". Dentro do movimento feminista, o termo se refere ao processo de fortalecimento da mulher para lutar contra as diversas formas de opressão.

No jornalismo, O empoderamento pode estar refletido na postura de uma mulher jornalista, nos textos que produz, nas fontes, entre outros. No blog Dibradoras, é nítido que - discurso das jornalistas é identificado com o feminismo e com sua luta para conseguir melhorias para as mulheres. Elas adotam uma postura de resistência, de expor a realidade e de fortalecer as outras mulheres nesse ambiente e, por isso, contribuem para a 
desconstrução da narrativa cultural hegemônica, que considera que as elas não podem se inserir e participar desse espaço.

\section{CONSIDERAÇÕES FINAIS}

Nesta pesquisa, tateamos alguns aspectos acerca da narrativa cultural hegemônica a respeito da relação da mulher com o futebol para discutirmos como ela está sendo desconstruída por alguns discursos jornalísticos. Como podemos perceber, de modo geral, a inserção e a participação das mulheres na prática do futebol feminino passou por dificuldades, incluindo a não aceitação e até uma proibição em lei.

Na análise das dez matérias do blog Dibradoras, constatamos, por meio das FDs, que os discursos são contrahegemônicos, pois rompem com relações de gênero e de poder predominantes e com conhecimentos e concepções sociais historicamente arraigados na nossa cultura. No blog, O discurso jornalístico almeja e indica mudanças na cultura para conquistar a igualdade de gênero ao colocar "a boca no trombone" para expor a realidade (FD denuncista), ao reforçar que lugar de mulher é onde ela quiser (FD demarcatória), ao criticar as situações de dois pesos, duas medidas (FD distintiva), ao evidenciar e exigir mudanças no mundo do futebol (FD da mudança) e ao empoderar mulheres para fortalecê-las na luta contra o machismo (FD da resistência).

Com a análise das FDs, consideramos que o discurso jornalístico do blog Dibradoras impõe resistência contra a estrutura machista da cultura e fortalece a luta pela igualdade de gênero. A contribuição do feminismo é evidente no discurso pela maneira como as autoras se posicionam no texto e pelas críticas e indignações que surgem diante das situações negativas enfrentadas pelas mulheres, fazendo com que outras mulheres se identifiquem por partilharem dessa indignação e revolta.

Compreendemos que 0 discurso jornalístico do blog Dibradoras promove a desconstrução da narrativa cultural hegemônica de estereotipação, subjugação, preconceito, discriminação e violência construída para manter as mulheres longe do futebol, não ocupando e não ameaçando um espaço reservado aos homens. Por meio da reflexão a respeito da realidade das mulheres no futebol, que também é um espaço de luta e resistência feminista, observamos as desigualdades que precisam ser combatidas e as exigências por transformações nesse meio e na cultura, a fim de que as mulheres alcancem a igualdade de gênero.

\section{NOTAS}

[1] Blog Dibradoras. Disponível em: https://dibradoras.blogosfera.uol.com .br/. Acesso em: 18 abr. 2019.

\section{REFERÊNCIAS}

BAGATINI, Olga. As barreiras das mulheres no jornalismo esportivo. Think Olga. São Paulo, 18 set. 2018 Disponivel em: https://bit.ly/3gal6Tr. Acesso em: 15 set. 2019

BEAUVOIR, Simone de. O segundo sexo l: fatos e mitos. São Paulo: Difusão Europeia do Livro, 1970

O segundo sexo II: a

experiência vivida. São Paulo: Difusão Europeia do Livro, 1967.

BIROLI, Flávia. "Agentes imperfeitas: contribuições do feminismo para a análise da relação entre autonomia preferências e democracia". Revista Brasileira de Ciência Política, (9), p.738, 2012. Disponível em: https://bit.ly/2M4y9x8. Acesso em: 01 nov. 2019.

"Mídia, tipificação e exercícios de poder: a reprodução dos estereótipos no discurso jornalístico". Revista Brasileira de Ciência Política, (6), p.71-98, 2011. Disponível em https://bit.ly/2zDT6MF. Acesso em: O2 nov. 2019

BRASIL. Constituição da República Federativa do Brasil. Brasília, DF: Senado Federal, 1988. Disponível em https://bit.ly/2zrTa2g. Acesso em: o8 set. 2019.

CAPITANIO, Ana Maria. Mulher, gênero e esporte: a análise da auto-percepcão das desigualdades. 2005. $103 f$ Dissertação (Escola de Educação Física e Esporte) - Universidade de São Paulo, São Paulo, 2005. Disponível em: https://bit.ly/2AdbMmA. Acesso em: 24 mar. 2019

COELHO, Paulo Vinicius. Jornalismo esportivo. São Paulo: Contexto, 2004

CRUZ, Sabrina Uzêda da. "A representação da mulher na mídia: um olhar feminista sobre as propagandas de cerveja". Travessias, 2(2), p.1-15, $2008 . \quad$ Disponível em: https://bit.ly/3c341Na. Acesso em: 10 nov. 2019

DIBRADORAS. Blog Dibradoras, UOL. São Paulo, 2019. Disponível em: https://dibradoras.blogosfera.uol.com. $\mathrm{br} /$. Acesso em: 18 abr. 2019 
ESCOSTEGUY, Ana Carolina Damboriarena. "Uma introdução aos Estudos Culturais". Revista Famecos, 5(9), p.87-97, 1998. Disponível em: https://bit.ly/2ZK2uZU. Acesso em: 09 mar. 2019.

FRANZINI, Fábio. "Futebol é "coisa para macho"? Pequeno esboço para uma história das mulheres no país do futebol". Revista Brasileira de História, 25(50), p.315-328, 2005. Disponível em: https://bit.ly/2TNNw1k. Acesso em: 26 jul. 2019

FREITAS, Bruno; MONTAGNANA, Laís; CARNEIRO, Leandro. "Intrusas" no gramado. UOL Esporte. São Paulo, 2016. Disponível em: https://bit.ly/2X5kNXQ. Acesso em: 15 set. 2019.

GARCIA, Carla Cristina. Breve história do feminismo. São Paulo: Claridade, 2011.

GOELLNER, Silvana Vilodre. "Mulheres e futebol no Brasil: entre sombras e visibilidades". Revista Brasileira de Educação Física e Esporte, 19(2), p.43151, 2005a. Disponível em: https://bit.ly/2zEOB4q. Acesso em: 16 mar. 2019.

"Mulher e esporte no Brasil: entre incentivos e interdições elas fazem história". Pensar a Prática, 8(1), p.85-100, 2005b. Disponível em: https://bit.ly/3gqlWzz. Acesso em: 28 jul. 2019.

GUSTAFSON, Jessica; NASCIMENTO, Fernanda. "O jornalismo como prática discursiva de transformação social ou de manutenção das desigualdades de gênero?". Revista Comunicação, Cultura e Sociedade, 1(1), p.32-48, 2017. Disponível em: https://bit.ly/3gDvqZI. Acesso em: 02 nov. 2019

HALL, Stuart. "Estudos Culturais e seu legado teórico". In: SOVIK, Liv (Org.). Da Diáspora: identidades e mediações culturais. Belo Horizonte: Editora UFMG; Brasília: Representação da Unesco no Brasil, 2003, p.199-218.
HOROCHOVSKI, Rodrigo Rossi; MEIRELLES, Giselle. Problematizando o conceito de empoderamento. In: Anais do II Seminário Nacional Movimentos Sociais, Participação E Democracia, 2007, Florianópolis-SC. Anais... Florianópolis: UFSC, 2007. p.485-506. Disponível em: https://bit.ly/2TKXWi7. Acesso em: O2 nov. 2019

MARQUES, Ester. Estruturas do discurso jornalístico. In: Anais do $X$ Congresso de Ciências da Comunicação no Nordeste INTERCOM NORDESTE, 2008, São Luís-MA. Anais... São Luís: UFMA, 2008, p.1-15. Disponível em: https://bit.ly/2TLOpcf. Acesso em: 28 set. 2019

MENDONCA, Renata. Estudo da Fifa mostra descaso de anos do Brasil com o futebol feminino. Blog Dibradoras, UOL. São Paulo, 16 jul. 2019a. Disponível em: https://bit.ly/36yBloC. Acesso em: 15 set. 2019

O futebol feminino já foi visto assim - o que diriam dessas imagens hoje?. Blog Dibradoras, UOL. São Paulo, 22 maio 2019b. Disponível em: https://bit.ly/3d9YW7d. Acesso em: 04 out. 2019

Por que não há mulheres na arbitragem da Copa - nem no VAR? Blog Dibradoras, UOL. São Paulo, 26 set. 2018. Disponivel em: https://bit.ly/3abOdcc. Acesso em: O8 set. 2019

MONTEIRO, Igor Chagas. Mulheres de preto: trajetórias na arbitragem do futebol profissional. 2016. $129 \mathrm{f}$ Dissertação (Programa de PósGraduação em Educação Física) Universidade Federal de Juiz de Fora Juiz de Fora, 2016. Disponível em: https://bit.ly/2TIclpM. Acesso em: 08 set. 2019
MOUFFE, Chantal. Feminismo ciudadanía y política democrática radical. Debate Feminista,

7. p.3-22, 1993. Disponível em: https://bit.ly/3evX6hj. Acesso em: 04 maio 2020.

MOURA, Eriberto José Lessa de. As relações entre lazer, futebol e gênero. 2003. 112f. Tese (Faculdade de Educação Física) - Universidade Estadual de Campinas, Campinas, 2003. Disponível em: https://bit.ly/3eBU4bp. Acesso em: 08 set. 2019.

NINA, Roberta. Final da Supercopa da UEFA será apitada pela $1^{a}$ vez por uma mulher. Blog Dibradoras, UOL. São Paulo, 02 ago. 2019. Disponível em: https://bit.ly/2X60ERi. Acesso em: 27 set. 2019.

ORLANDI, Eni Puccinelli. Análise de discurso: princípios e procedimentos. Campinas, SP: Pontes, 2013.

PATEMAN, Carole. O contrato sexual. Rio de Janeiro: Paz e Terra, 1993.

SCOTT, Joan. "Gênero: uma categoria útil de análise histórica". Revista Educação e Realidade, 20(2), p.71-99, 1995. Disponível em: https://bit.ly/3c7IPFK. Acesso em: 27 abr. 2019

SILVA, Marcia Veiga da. Masculino, o gênero do jornalismo: um estudo sobre os modos de produção das notícias 2010. 249f. Dissertação (Programa de Pós-Graduação em Comunicação e Informação) - Universidade Federal do Rio Grande do Sul, Porto Alegre, 2010 Disponível em: https://bit.ly/2M61qYo Acesso em: 07 set. 2019

\section{Artigo recebido em: 13 Abr. 2020. I Artigo aprovado em: 08 Maio 2020.}

[i]Professora e subcoordenadora dos Cursos de Comunicação e Fotografia da Universidade de Santa Cruz do Sul (UNISC). Doutora em Comunicação Midiática pela Universidade Federal de Santa Maria (UFSM). Jornalista e Mestre em Desenvolvimento Regional pela Universidade de Santa Cruz do Sul (UNISC). Orcid: http://orcid.org/0000-0002-2119-6220

E-mail: patriciaschuster@unisc.br

[ii]Graduanda no Curso de Comunicação Social, na habilitação de Jornalismo, na Universidade de Santa Cruz do Sul (Unisc). Ordic: http://orcid.org/0000-0003-0772-2439

E-mail: fernandandsilveira@gmail.com 